\title{
DANO EXISTENCIAL: A ESPECIFICIDADE DO INSTITUTO DESVELADO A PARTIR DA VIOLAÇÃO AO DIREITO DE DESCONEXÃO DO EMPREGO
}

\author{
EXISTENTIAL DAMAGE: THE SPECIFICITY OF THE INSTITUTE UNVEILED \\ FROM THE VIOLATION TO THE RIGHT OF LABOR DISCONNECTION.
}

\author{
${ }^{1}$ Angela Barbosa Franco
}

\section{RESUMO}

O Direito à desconexão ao trabalho está pautado em uma prerrogativa constitucional e fundamental de toda classe obreira. Os intervalos para descanso do ambiente laboral são tutelados por lei e têm como escopo proporcionar aos trabalhadores e às trabalhadoras a recuperação de suas energias físicas e psíquicas. Também asseguram momentos de pleno deleite, de inserção familiar, comunitária, política e de privacidade para a realização de planos pessoais. A violação desses períodos de desconexão pode comprometer projetos ou hábitos de vida, assim como o convívio social, acarretando um dano existencial. A partir dessas premissas, o presente artigo objetiva analisar os elementos caracterizadores do dano existencial para evidenciar suas particularidades em relação ao dano moral e para defender a acumulação dos danos para a justa reparação da vítima e de sua dignidade como ser humano. Para isso, a pesquisa pauta-se na vertente jurídico-dogmática, pois considera os elementos internos do ordenamento jurídico suficientes para estabelecer uma distinção entre as lesões morais e as existenciais. O cerne do problema encontra-se nos elementos tipificadores do dano existencial que, por terem origem extrapatrimonial e nos direitos personalíssimos, são equivocadamente considerados pelos tribunais trabalhistas como uma espécie de dano moral e limitam as possibilidades de indenização do lesionado. Sob esta perspectiva, a complexidade contextual apresentada é superada por meio de um raciocínio dedutivo, ao indicar, nas normas abertas do sistema legal pátrio, a possibilidade de uma investigação interdisciplinar e comparativa que comprove as especificidades dos danos morais e existenciais.

Palavras-chave: Dano existencial, Direito de desconexão, Especificidade do dano existencial, Acumulação dos danos

\footnotetext{
${ }^{1}$ Mestre em Direito pelo Faculdades Milton Campos, Minas Gerais (Brasil). Professora da Escola de Estudos Superiores de Viçosa - ESUV, Minas Gerais (Brasil). E-mail: catfranco20@ hotmail.com
} 


\begin{abstract}
The right of labor disconnection underlies on a constitutional and fundamental prerogative of the entire working class. Rest periods from the laboring environment are protected by law and have the objective to provide workers with recovery of their physical and mental energies. They also assure moments of delight, of family, communitarian and political insertion, for the fulfillment of personal plans. The violation of these disconnection periods can jeopardize projects or life habits, as well as social relations, resulting in existential damage. From these premises, this article aims to analyze the characterizing elements of existential damage in order to evince its peculiarities in relation to moral damage and to defend the accumulation of damages to provide just atonement to the victims and to their dignity as human beings. Thus, this research supports itself on legal dogmatic principles, since it considers that the internal elements of legal order are sufficient to establish a distinction between moral and existential injuries. The main problem relies on the typifying elements of existential damage. Due to their extra-patrimonial nature and relationship to personal rights, they are mistakenly considered by labor courts as moral damages, and, therefore, given limited possibilities of indemnification to the victim. Under this perspective, the contextual complexity above presented is overcome through deductive reasoning, as it indicates in the open norms of the national legal system the possibility of an interdisciplinary and comparative investigation which attests the specificities of moral and existential damages.
\end{abstract}

Keywords: Existential damage, Right of disconnection, Specificity of existential damage, Damage accumulation 


\section{INTRODUÇÃO}

A condição de incerteza e efemeridade inerentes à vida induz o ser humano a fazer projetos que dão sentido à sua existência. A liberdade para batalhar por esses anseios prospectivos chega a ser mais importante do que a própria concretização.

Quando uma pessoa, arbitrariamente, impede ou molesta os planos de existência de outra, acarreta-lhe um dano irreparável ou de difícil reparação. No ambiente de trabalho, essa lesão tem se materializado de diversas formas e destaca-se diante de um universo globalizado pela tecnologia, sem limites para interação virtual. Modernamente, o período diário de oito horas à disposição da hierarquia patronal é extrapolado de maneira contumaz e invasiva pelas facilidades dos meios de comunicação. Apesar de a classe obreira não estar mais dentro do espaço físico da empresa, ou do lapso temporal máximo ajustado para execução de serviços, continua a realizar tarefas profissionais quando, para atender à demanda laboral, utiliza-se celulares, aplicativos online, computadores, tablets, dentre outros instrumentos tecnológicos,. Sob essa perspectiva, acredita-se que se o trabalhador é compelido a portar qualquer tipo de aparelho de comunicação, em seus intervalos para descanso, para se manter integrado às atividades laborais, sua vida pode ser negativamente afetada, com o cerceio ao direito de desconexão.

O Direito à desconexão ao trabalho está pautado em uma prerrogativa constitucional e fundamental de toda a casta laboriosa. Os intervalos para descanso do ambiente patronal são tutelados por lei e têm como escopo proporcionar aos trabalhadores e às trabalhadoras a recuperação de suas energias físicas e psíquicas. Também asseguram momentos de pleno deleite, de inserção familiar, comunitária, política e de privacidade para a realização de planos pessoais. A violação desses períodos para repouso pode comprometer projetos ou hábitos de vida, assim como o convívio social, acarretando um dano existencial.

Nesse contexto, o presente trabalho destaca a realidade vivenciada pela classe trabalhadora em ter que se manter a todo o momento conectada, atualizada e integrada a diversos meios de comunicação para ficar sempre à disposição dos afazeres da empresa no cumprimento de demandas laborais. Essa constante violação do direito ao não trabalho durante os intervalos intrajornada, interjornada, de repouso semanal, bem como após a jornada padrão estipulada legalmente, é capaz de comprometer a saúde, a serenidade familiar, as relações afetivas, as atividades biológicas, culturais, religiosas, educacionais e recreativas. Dessa forma, essa situação laboral não pode ser banalizada pelo ordenamento jurídico. 
Assim, o tema ora proposto tem relevância jurídica e é oportuno, ao considerar que a renúncia involuntária às tarefas cotidianas, desvinculadas do orbe laboral, bem como aos planos pessoais, afeta a liberdade e a intimidade da parte hipossuficiente da relação de emprego e culmina em um dano à existência. Este dano é fruto da transgressão de direitos indisponíveis e irrenunciáveis do ser humano e possui fundamentos e características específicas que o difere do dano moral.

Diante dessas premissas, o presente artigo objetiva analisar os elementos caracterizadores do dano existencial para evidenciar suas particularidades em relação ao dano moral e para defender a acumulação dos danos para a justa reparação da vítima e de sua dignidade como ser humano. O cerne do problema encontra-se nos elementos tipificadores do dano existencial que, por terem origem extrapatrimonial e nos direitos personalíssimos, são equivocadamente considerados pelos tribunais trabalhistas como uma espécie de dano moral, limitando as possibilidades de indenização do lesionado.

Para isso, a pesquisa pauta-se na vertente jurídico-dogmática, pois considera os elementos internos do ordenamento jurídico suficientes para estabelecer uma distinção entre as lesões morais e as existenciais. Sob essa ótica, a complexidade contextual apresentada é superada por meio de um raciocínio dedutivo, ao indicar, nas normas abertas do sistema legal pátrio, a possibilidade de uma investigação interdisciplinar e comparativa que comprove as especificidades dos danos morais e existenciais.

O estresse da competitividade, diante de um mercado marcado pelo desemprego, desumaniza a classe empregada que não mede esforços para atender os anseios do empregador. Dentro desse cenário, a saúde do trabalhador encontra-se vulnerável pela disponibilidade desmedida ao trabalho, promovida e facilitada pela tecnologia, aumentando a possibilidade de acidentes de trabalho devido ao cansaço inevitável. Defende-se, assim, a imprescindibilidade do reconhecimento do dano existencial, como instituto autônomo do dano moral, para se ter a plena reparação do dano injusto e valorização da dignidade da pessoa do trabalhador. 


\section{A LESÃO AO DIREITO DE DESCONEXÃO PELA TECNOLOGIA COMO FATOR DESENCADEADOR DO DANO EXISTENCIAL}

A classe obreira dedica grande parte de sua vida ao cumprimento das obrigações trabalhistas e à satisfação dos interesses da classe patronal, por isso, necessita de repouso das atividades laborais para não perder sua dimensão humanística.

As normas que tutelam o direito de desconexão do ambiente de trabalho objetivam a recomposição das energias empregadas para melhor vocacioná-las ao atendimento das exigências do empregador e não podem ficar superficialmente adstritas à preservação da integridade física ou psíquica dos trabalhadores. Os intervalos para descanso têm cunho social e visam resguardar o bem-estar, o convívio familiar, as atividades recreativas, políticas, culturais, espirituais, afetivas, enfim, toda e qualquer experiência que promova a felicidade e realização do ser humano.

No ordenamento jurídico brasileiro, o direito de desconexão relaciona-se aos direitos fundamentais à saúde, higiene e segurança no trabalho que estão elencados no texto da Constituição da República Federativa do Brasil de $1988^{1}$. Os períodos de repouso como as férias, os intervalos intrajornada, interjornada e intersemanal, as hipóteses de interrupção e suspensão do contrato de trabalho, dentre outras, encontram-se positivados na Consolidação das Leis do Trabalho ${ }^{2}$ e diversas leis esparsas ${ }^{3}$. Tais normas desvelam a preocupação do legislador com o repouso do trabalho para a incolumidade da vida dos laboriosos. Contudo, o avanço tecnológico e a globalização nas relações de trabalho, com a utilização de modernos e diversos meios de comunicação, têm acarretado a violação contumaz das pausas no labor consideradas pelo Direito do Trabalho prerrogativas indispensáveis de trabalhadoras e trabalhadores.

\footnotetext{
${ }^{1}$ Artigo $7^{\circ}$, incisos XIII, XIV, XV, XVII, XXII (BRASIL, 1988).

${ }^{2}$ Artigos 129 a $153 ; 66 ; 67 ; 71 ; 131 ; 472 ; 473$ a 476-A (BRASIL, 1943).

${ }^{3}$ Como exemplo cita-se a Lei 605 de 5 de janeiro de 1949 (BRASIL, 1949).
} 
Atualmente a exploração do trabalho à distância ou remoto é crescente e facilitada por instrumentos de telecomunicação e informática. O uso de celulares, aplicativos da telefonia móvel, internet, localizadores, câmeras, dentre outros meios de controle e monitoramento, permitem um contato constante entre os sujeitos da relação de emprego e a execução de serviços em diversos locais e horários, ainda que não exista nenhum contato pessoal. Dessa forma, a interação proporcionada pela tecnologia restringe a liberdade e a intimidade da classe trabalhadora nos períodos de descanso que deveriam ser, impreterivelmente, preservados.

Sob essa perspectiva, Cassar (2010) preceitua que o direito ao não trabalho é infringido devido ao estresse enfrentado pelo trabalhador ao sentir constantemente pressionado em se atualizar e se integrar ao emprego. Com isso, o obreiro sofre fadiga mental ou encontrase escravizado ao vício de, a todo o momento, manter-se conectado com o serviço, inclusive nos intervalos destinados ao descanso. Para Souto Maior (2003), apesar de a tecnologia ser um fator determinante da vida moderna e afetar o direito de desconexão ao trabalho, não pode ser evitada em um mundo marcado pelo temor do desemprego. Assim, a necessidade de se informar e saber acessar os meios de informação é inevitável para se sustentar no mercado. Em contrapartida, os direitos ao repouso e à privacidade, para o pleno desligamento da dinâmica laboral e dos problemas decorrentes do trabalho, são mitigados e acabam por impossibilitar o empregado de desfrutar do convívio social, familiar ou de realizar projetos de vida.

Essa restrição ao relacionamento social e frustração aos planos pessoais, bem como profissionais, acarreta um dano para o trabalhador devido ao vazio existencial gerado pelo desrespeito de livremente dispor de seu tempo da maneira que lhe convier, sem acarretar prejuízo a terceiros (BEBBER, 2009). Tal fenômeno, nominado dano existencial, é explicado por Soares (2009, p. 44) como um acontecimento negativo, comprometedor do "complexo de afazeres da pessoa, sendo suscetível de repercutir-se, de maneira consistente - temporária ou permanentemente - sobre sua existência”. Assim, afeta diversos momentos ou setores da vida do indivíduo.

Quando o trabalhador é compelido a portar qualquer tipo de aparelho de comunicação para ser encontrado, chamado, controlado, ou estar conectado, a fim de melhor desempenhar suas funções fora do espaço físico do empregador e após a jornada de trabalho, deve ser remunerado, pois continua, de certa forma, à disposição da empresa. As horas de sobreaviso e prontidão, por exemplo, apesar de a lei exigir o pagamento, conforme dispõe o 
artigo 244, $\S 2^{\circ}$ e $\S 3^{\circ}$, da Consolidação das Leis do Trabalho (BRASIL, 1943), não permitem a efetiva desativação do trabalho. Mesmo à distância, fora da fiscalização direta e imediata do tomador de serviços, o empregado tem sua liberdade e sua privacidade cerceadas, com a expectativa de a qualquer momento ser molestado pelas tarefas laborais. Dessa forma, embora exista a efetiva contraprestação pecuniária, regulamentada e imposta ao patronato, "não se pode comparar o empregado que, ao final da jornada, pode se desligar do trabalho e relaxar, com aquele que, apesar de ter saído do ambiente de trabalho ao final da jornada, ainda leva consigo um prolongamento do ofício" (CASSAR, 2010, p. 189). Se o direito fundamental ao não trabalho é prescindido com os incômodos da modernidade e impede o total afastamento do ambiente de trabalho, a liberdade e a privacidade do trabalhador devem ser reparadas caso sejam comprovadamente afetadas.

Conveniente também destacar que a inobservância à desconexão ao trabalho pode implicar em privações na vida de trabalhadores e trabalhadoras, ao exigir-lhes, habitualmente, jornadas extraordinárias, mesmo dentro dos limites permitidos pela lei. Ainda que a jornada não venha ultrapassar o máximo de horas recomendado pela legislação, o exagero de obrigações, impostas por quem dirige a prestação pessoal dos serviços, esgota o empregado e compromete seus momentos de lazer ou contato com a família e amigos. É forçoso haver um equilíbrio entre a pretensão do empregador de usar a mão de obra humana da forma que lhe for mais proveitosa e o interesse do trabalhador em satisfazer as exigências de sua vida privada e familiar. (BALLESTRERO, 2009). O tomador de serviços não deve sacrificar seus trabalhadores a ponto de lhes suprimir tempo e energia necessários para se dedicarem às relações familiares.

\section{O DANO EXISTENCIAL E SUAS ESPECIFICIDADES}

O dano existencial é configurado quando ocorre a frustração de projetos de vida ou o comprometimento da vida de relações de empregados e empregadas (FROTA, 2013). Esses elementos devem estar acompanhados por um ato ilícito, um efetivo prejuízo e um nexo de causalidade entre eles (BOUCINHAS FILHO: ALVARENDA, 2013). Desse modo, faz-se necessária a identificação de uma conduta patronal como ilícita e, devido a ela, o obreiro sofra alguma lesão por ser impedido de desenvolver seus projetos ou de realizar escolhas pessoais. 
A mera não permissão de férias dentro dos períodos concessivos ou a sobrecarga de horas extraordinárias, por exemplo, não gera, por si só, o dano existencial. A legislação prescreve punições próprias como a multa administrativa, o pagamento em dobro das férias e das horas suplementares, com o devido adicional de hora extra ${ }^{4}$. Por isso, faz-se imprescindível a comprovação do dano ao projeto de vida ou ao convívio social. O direito precisa tutelar não apenas a violação patrimonial da classe trabalhadora, pela inadimplência do empregador quanto ao pagamento da sobrejornada habitual ou da ausência de férias por um longo período, mas de um mal à própria existência do trabalhador enquanto pessoa e ser social (NASCIMENTO, 2014). Assim, um fato injusto praticado pelo superior hierárquico, que desvirtue planos porvindouros de seus subordinados e obste suas escolhas, sonhos, metas ou ideais de tudo aquilo que anseia realizar, bem como obrigue a pessoa a resignar-se com o seu futuro, fundamenta a presença do dano existencial (BEBBER, 2009). Isso significa que o direito de planejar, independente da concretização, não pode ser tolhido, sob pena de retirar do indivíduo o sentido a sua própria essência.

Os projetos de vida representam planos do ser humano capazes de lhe dar bem-estar, felicidade ou realização. Para ensejar a frustração de projetos e a materialização de um dano injusto, é preciso a comprovação da inexecução de uma pretensão razoável e dentro da normalidade. Nos dizeres de Bebber (2009, p. 29), "é necessário haver possibilidade ou probabilidade de realização do projeto de vida". Os atos passados e presentes pressupõem a concretização de um fato futuro. Se a pessoa realiza ações que lhe aproxima da consolidação de seus sonhos, planos ou metas, o abortamento destes, causado por um ato injusto de terceiro, pode lhe gerar um dano à existência, caso acarrete na reprogramação, com limitações, de seus ideais. Sob essa ótica, cita-se a decisão do Tribunal Regional do Trabalho da $4^{\text {a }}$ Região que, ao apreciar os autos sobre pedido de indenização da trabalhadora devido à jornada excessiva, com labor aos sábados e, inclusive, aos domingos, reconhece o dano existencial caracterizado pelo término da relação conjugal e, consequentemente, necessária mudança no curso de vida. Segundo o Desembargador relator,

\footnotetext{
${ }^{4}$ Artigo 137 da Consolidação das Leis do Trabalho (BRASIL, 1943) e artigo $7^{\circ}$, inciso XVI, da Constituição da República Federativa do Brasil (1988).
} 
De fato, a reclamante tinha poucas horas para dedicar-se, por exemplo, ao descanso, ao convívio familiar e social e ao lazer, atividades que orientam o plano existencial de cada indivíduo. No caso, a repercussão nociva do trabalho na reclamada na existência da autora é evidenciada com o término de seu casamento enquanto vigente o contrato laboral, rompimento que se têm como lastreado nas exigências da vida profissional da autora. (RIO GRANDE DO SUL, 2014, p. 23).

Para corroborar as ideias expostas, Almeida Neto (2005, p. 62) assevera:

O dano existencial, em suma, causa uma frustração no projeto de vida do ser humano, colocando-o em uma situação de manifesta inferioridade - no aspecto de felicidade e bem-estar - comparada àquela antes de sofrer o dano, sem necessariamente importar em um prejuízo econômico. Mais do que isso, ofende diretamente a dignidade da pessoa, dela retirando, anulando, uma aspiração legitima (...)

No que cerne à vida de relação, “o dano resta caracterizado, na sua essência, por ofensas físicas ou psíquicas que impeçam alguém de desfrutar total ou parcialmente dos prazeres propiciados pelas diversas formas de atividades recreativas e extralaborativas" (BOUCINHAS FILHO; ALVARENDA, 2013, p. 40). Viagem com amigos ou família, a prática de esportes, o prazer de uma leitura descompromissada, de um passeio ao clube, de assistir ao cinema ou ao teatro, de participar de uma reunião com os vizinhos, de desfrutar das celebrações de aniversário ou de casamento dos familiares e amigos, de escutar uma música, de deleitar-se em hobbies ou em diversas outras formas de convívio social, são ações que garantem um momento de relaxamento, de lazer, de tranquilidade para a espécie humana. No entanto, apenas tornam-se desfrutáveis pela parte hipossuficiente da relação de emprego se os direitos fundamentais ao repouso e à privacidade são gozados em sua plenitude.

Interessante asseverar que a lesão existencial não requer repetições ou sequência de atos abusivos do superior hierárquico. Sob essa perspectiva, Boucinhas Filho e Alvarenga (2013, p. 41) elucidam:

É fácil imaginar o dano causado à vida de relação de determinado empregado em decorrência de condutas ilícitas regulares do empregador, como a constante utilização de mão de obra em sobrejornada, impedindo o empregado de desenvolver regularmente outras atividades em seu meio social. Não se pode, contudo, descuidar da hipótese de o dano à vida de relação poder ser causado por um único ato. Um bom exemplo seria o do empregador que compele determinado empregado a terminar determinada tarefa, que não era tão urgente ou que poderia ser concluída por outro colega, no dia, por exemplo, da solenidade de formatura ou de primeira eucaristia de um de seus filhos, impedindo-o de comparecer à cerimônia. 
Note-se, assim, que uma ação do tomador de serviços é o suficiente para gerar uma perda irreparável ao empregado ou à empregada quando arruinar uma oportunidade impossível de ser vivenciada novamente. A habitualidade não é elemento crucial na identificação do dano existencial, mas sim a afronta à dignidade da pessoa humana e aviltamento da vida privada, social e familiar.

Oportuno, novamente, asseverar que a jornada extenuante, ainda devidamente paga com o adicional nunca inferior a cinquenta por cento da hora normal do trabalhador, enseja dano existencial. Ampliam-se as possibilidades de acidente de trabalho ou de desenvolvimento de doenças ocupacionais e colocam em risco a saúde física e mental de quem é empregado. As infortunísticas laborais não têm como serem economicamente compensadas, pois de nada vale o pagamento do adicional de horas extras quando uma lesão futura é iminente. Se a incolumidade física e a psíquica não são preservadas durante a atividade profissional e comprometem a vida extralaboral ao restringir ou impedir outros afazeres da vida comezinha, confirmada está a lesão existencial. Nesse aspecto, Boucinhas Filho e Alvarenga (2013) mencionam a LER, Lesão por Esforços Repetitivos, para exemplificar o dano existencial. A doença obriga o acometido a reprogramar sua rotina por não conseguir realizar as mesmas atividades anteriores à lesão.

Quando o trabalhador é vítima de lesão por esforços repetitivos, ele não padece apenas de um dano à sua saúde, mas também de um consequente dano existencial. A razão é a seguinte: lesão por esforços repetitivos atinge o sistema músculo-esquelético da pessoa, principalmente os membros superiores; sendo assim, pode, em estágio avançado, gerar a incapacidade para diversas atividades. A lesão por esforços repetitivos decorre de uma exposição descontrolada aos fatores que a desencadeiam, exposição essa geralmente determinada por iníquas condições de trabalho às quais o trabalhador pode ser submetido. (BOUCINHAS FILHO; ALVARENDA, 2013, p. 46).

Soares (2009) pontua o acidente de trabalho como um infortúnio evidenciador do dano existencial. O sinistro que acomete o empregado pode

(...) tornar facetas do cotidiano que, até então, pareciam triviais ou corriqueiras um momento de profunda angústia, tensão, dificuldade e frustração, como ir e vir, dirigir um automóvel, tomar um ônibus, manter relações sexuais com o marido ou a esposa, o companheiro ou a companheira, deixar os filhos no colégio, ler um livro, entabular uma tertúlia despretensiosa com amigos e parentes, andar na rua sem estar em estado de alerta ou entrar em espaço fechado sem sentir asfixiado. (FROTA, 2013, p. 27-28) 


\section{A ACUMULAÇÃO DO DANO EXISTENCIAL COM OUTRAS ESPÉCIES DE} DANO

A Carta Máxima (BRASIL, 1988), nos artigos $5^{\circ}$, caput e inciso V, $6^{\circ}$, caput, e $7^{\circ}$ XXII, XXIII e XXVIII, impõe ao empregador o respeito à vida, saúde, moral e imagem do trabalhador, bem como a obrigação de adotar medidas para reduzir os riscos inerentes ao trabalho e, ainda, reparar os danos causados aos empregados, na exata proporção dos danos materiais, morais, estéticos, existenciais e outros que vierem a ser experimentados (ALMEIDA, 2003). Assim, não apresenta um rol taxativo, mas fundamenta a responsabilidade o sujeito da relação de emprego causador de alguma lesão a outrem.

Quem sofre uma lesão aos seus bens materiais e imateriais pode pleitear diversos tipos de ressarcimento como a indenização por dano material, dano moral, dano estético, dano existencial, perda de uma chance, dentre outras. Cada uma delas é baseada em peculiaridades diversas e devem ser cumulativamente exigidas.

No contexto da relação de emprego e dos acidentes de trabalho, os danos patrimoniais consistem nas despesas com tratamento médico ou hospitalar do obreiro e, também, dispêndios com "a redução da capacidade laboral, com prejuízos ao valor do seu trabalho e à possibilidade de recolocação no mercado de trabalho, e perda da capacidade para o trabalho, afetando o crescimento profissional e social do trabalhador" (ALMEIDA, 2003, p. $37)$.

O dano moral relaciona-se à ocorrência de transgressões aos direitos de personalidade do trabalhador durante o labor e nas relações jurídicas conexas. Para Cassar (2011, p. 961),

é o resultado de uma ação, omissão ou decorrente de uma atividade de risco que causa lesão ou magoa bens ou direitos da pessoa, ligados à esfera jurídica do sujeito de direito (pessoa física, pessoa jurídica, coletividade etc). É o que atinge o patrimônio ideal da pessoa ou do sujeito de direito.

A lesão de cunho moral afeta o sentimento e manifesta-se de maneira variada, ao se considerar que cada ser tem sensibilidades diferentes dos outros. A intensidade do sofrimento causado pelo empregador varia de acordo com a particularidade ou a intimidade dos prejudicados.

O dano estético vincula-se à imagem e corresponde a um defeito físico como “aleijões, deformidades, deformações e marcas" (ALMEIDA, 2003, p. 37). A normalidade natural da pessoa não deve ser confundida com a beleza. Aquela pode ser lesada, por 
exemplo, com uma cicatriz ou a amputação de um membro que desperte a curiosidade dos outros, mas o direito à reparação não resulta de uma cicatriz repulsiva, tampouco sanada mediante cirurgia plástica. O ressarcimento justifica-se quando o dano torna a pessoa diferente ou lhe inferioriza em relação aos seus semelhantes (GRANDOV; BASCARY, 2000). A anomalia que a vítima passa a ostentar, por ter alterado seu aspecto visual anterior à lesão, causa impacto não apenas a quem percebe, mas à própria vítima, abalada com a diminuição da harmonia corporal. Apesar de o dano estético, igualmente ao dano moral, ser tocante a valores personalíssimos inerentes a qualidade da pessoa humana, seu alicerce limitase à alteração da imagem antes do sinistro. Essa peculiaridade permite o reconhecimento de indenização independente do dano moral, de acordo com o entendimento na súmula 387 do Superior Tribunal de Justiça (2009): "é lícita a acumulação de dano estético e moral”.

No que cerne ao dano existencial e ao dano moral, os Tribunais Trabalhistas evidenciam certa confusão entre as espécies por pertencerem ao gênero dos danos imateriais. Nesse aspecto, cita-se a decisão do Tribunal Superior do Trabalho ao responsabilizar civilmente a empresa em não conceder férias por mais de 10 anos ao trabalhador. $\mathrm{O}$ acórdão sugere sofrer o reclamante algumas privações em sua vida e violações aos direitos de saúde e lazer, elementos do dano existencial, sem distingui-los do dano moral:

Trata-se de direito fundamental e inalienável do trabalhador, de modo que a reiteração da conduta omissiva da reclamada, ao descumprir dever contratual, consistente em norma básica de proteção à saúde do trabalhador, por mais de dez anos, ofende a dignidade humana do autor, pois não só o privou de usufruir de garantias fundamentais, como saúde, lazer, higidez física e mental, como pode resultar em doença do trabalho ou até deixar sequelas físicas ou psicológicas, tendo em conta o excesso de fadiga. (...)

Vale destacar ser desnecessária a prova do prejuízo moral no caso, já presumido da própria violação da personalidade do ofendido, o que autoriza o Juiz a arbitrar um valor para compensar financeiramente a vítima. Com efeito, o dano moral tem característica peculiar, in re ipsa, derivando da própria natureza do fato.(grifos nossos) (TST, 2012, p. 6).

Nascimento (2014) também não reconhece diferenciação e considera o dano existencial uma espécie de dano moral que deve ser reparada. Todavia, os danos moral e existencial não se confundem e precisam ser considerados autônomos devido às peculiaridades de cada lesão. Mesmo que derivem de um mesmo fato, possuem fundamentos variados. Bebber (2009) esclarece que enquanto o dano moral é subjetivo, o existencial é objetivo. Quando o prejuízo atinge sentimentos íntimos e diversificados em cada ser, como a dor, a vergonha, a 
angústia, a mágoa, dentre outros, tem-se o dano moral. Já o dano existencial não está vinculado às emoções, mas a um projeto de vida frustrado ou ao comprometimento da vida de relações. Assim, obriga o ofendido a se reprogramar diferentemente do que planeja ou tem hábito, prejudica o seu relacionamento familiar, social e os deleites do viver. Sob esse mesmo prisma, Soares (2009) defende a separação dos institutos ao afirmar que o dano moral ataca o sentir e o dano existencial limita-se ao não poder mais realizar ou a não fazer algo comum, obrigando o ser humano a se readaptar a uma nova realidade. A doutrinadora enfatiza que as lesões florescem em momentos distintos:

Enquanto o dano moral incide sobre o ofendido, de maneira, muitas vezes, simultânea à consumação do ato lesivo, o dano existencial, geralmente, manifesta-se e é sentido pelo lesado em momento posterior, porque ele é uma sequência de alterações prejudiciais no cotidiano, sequência essa que só o tempo é capaz de caracterizar. (SOARES, 2009, p. 46).

Atente-se, ainda, para o fato que o dano moral atinge tanto a pessoa física como a pessoa jurídica, conforme evidencia a súmula 227 do Superior Tribunal de Justiça. Em contraponto, o dano existencial é inerente apenas à pessoa física, pois afeta a vida íntima do ser humano.

Note-se que a indenização dos diversos danos deve ser a mais completa possível, seja em face dos princípios da igualdade e da não-discriminação, consagrados expressamente pela Constituição Federal de 1988 (BRASIL, 1988), e que impelem que a pessoa do trabalhador tenha o direito a ser ressarcido na exata medida dos danos por ele experimentado, seja porque o artigo $7^{\circ}$, inciso XXVIII, do mesmo diploma legal (BRASIL, 1988), não estabelece qualquer limite para responsabilidade reparatória que atribui ao empregador.

Boucinhas Filho e Alvarenga (2013) aduzem que a cumulação dos danos extrapatrimoniais ou patrimoniais precisam ser uma consequência do mesmo fato gerador e até vislumbram a inclusão do pedido de indenização pela perda de uma chance, quando existir incerteza quanto ao fato danoso em si:

Imaginemos o exemplo de um maratonista de alto nível que sofre um acidente de trabalho que o impossibilita de correr para o resto de sua vida às vésperas de uma corrida cuja premiação era de $\mathrm{R} \$ 50.000,00$ (cinquenta mil reais). Nesse caso, se está diante de hipóteses de dano moral, existencial e perda de uma chance. $\mathrm{O}$ dano moral pela frustração, pelo dissabor e pela dor provocada pelo ocorrido, a perda da chance de aumentar o patrimônio em $\mathrm{R} \$$ $50.000,00$ (cinquenta mil reais), decorrente da não participação da corrida, o dano existencial por não mais poder se dedicar a essa atividade esportiva.(BOUCINHAS FILHO; ALVARENDA, 2013, p. 51). 
De acordo com os autores supracitados, se evidenciado os fundamentos específicos da indenização pela perda de uma chance, cabe aos tribunais reconhecê-la. Aquele que retira a probabilidade de êxito de outrem, quando a oportunidade for séria e legítima, precisa assumir o ato danoso. Em uma relação de emprego essa possibilidade pode ser vislumbrada em diversas situações como a

exclusão do empregado do mercado em razão de incapacidade provocada por acidente de trabalho ou do fornecimento de informações desabonadoras pelo ex-empregador; impossibilidade de conclusão de concurso público em razão de acidente por culpa do empregador; perda da oportunidade de o empregador potencializar seus ganhos em razão de empregado em posição de destaque haver se desligado sem cumprir aviso prévio. (BOUCINHAS FILHO; ALVARENDA, 2013, p. 51).

A reparação, conforme susomencionado, pode, inclusive, ser imposta ao empregado, quando não comunicar, ao tomador de serviços, sua intenção de extinguir a relação de emprego, com trinta dias de antecedência, retirando-lhe, assim, o direito de ser previamente comunicado do aviso prévio e a chance de encontrar um substituto para cumprir as exigências da demanda empresarial.

Ante as possibilidades de reparação aqui pontuadas, defende-se que o dano existencial não pode ser banalizado, bem como considerado um mero desdobramento do dano moral ou a ele vinculado. Trata-se de uma situação específica, proveniente de uma lesão às expectativas de vida da classe profissional, passível de acumulação com as diversas formas de indenização já sedimentadas pelo ordenamento jurídico ao lesionado. Para isso, basta uma maior sensibilidade dos tribunais em seus julgados, evitando-se uma interpretação reducionista, quando os elementos peculiares do dano existencial, quais sejam, a frustração de projetos de vida e/ou o comprometimento da vida de relações, restarem indubitavelmente comprovados. O arcabouço legal para isso encontra-se na própria Carta Máxima (BRASIL, 1988), conforme já explicitado, bem como nas normas celetistas e esparsas, atinentes à saúde, à higiene e à segurança no trabalho, construídas com o intuito de preservar o direito de desconexão de todo empregado.

\section{CONSIDERAÇÕES FINAIS}

O ordenamento jurídico deve primar pela absoluta preservação e respeito aos direitos fundamentais de todo ser humano, inclusive o direito de desconexão do emprego. Se este é 
mitigado pela interferência do uso da tecnologia no trabalho, por ser a mesma um mecanismo inevitável da vida moderna, deve o tomador de serviços responder pelos excessos ou lesões provocados por sua interferência na privacidade da classe obreira. Deste modo, faz-se necessária a reparação aos danos existenciais acarretados pela não observância do direito à desconexão do emprego.

Para que a responsabilização da categoria patronal seja legítima, esta deve ser acompanhada por um ato ilícito, um efetivo prejuízo nos projetos de vida dos trabalhadores e/ou o comprometimento de suas relações sociais, bem como existir um nexo de causalidade entre eles. Esses elementos são fundamentos especiais e objetivos do dano existencial, que o distingue do dano moral, por ser este subjetivo, afeito ao sentimento e, consequentemente, mais amplo.

A separação dos institutos do dano moral e existencial revela-se imprescindível para a proteção total do ser humano, principalmente, diante de um contexto em que o universo laboral é marcado pela intensa escravização do empregado pela tecnologia, e, consequentemente, pela exaustão física e psíquica. Assim como os tribunais reconhecem a possibilidade de acumulação dos danos patrimoniais, morais e estéticos, deve-se incluir, nesse rol de desrespeito ao cidadão, o dano existencial, para que o lesionado seja efetivamente ressarcido na medida dos prejuízos por ele vivenciados, quando devidamente comprovados.

\section{REFERÊNCIAS}

ALMEIDA, Clélio Lúcio de. Responsabilidade civil do empregador e acidente de trabalho. Belo Horizonte: Del Rey, 2003.

ALMEIDA NETO, Amaro Alves de. Dano existencial: a tutela da dignidade da pessoa humana. Revista dos Tribunais, São Paulo, v. 6, out./dez. 2005.

BALLESTRERO, Maria Vittoria. La conciliazionetra lavoro e famiglia. Brevi considerazioni introduttive. Lavoro e Diritto, ano XXIII, n. 2, primavera, 2009.

BEBBER, Júlio Cesar. Danos extrapatrimoniais (estético, biológico e existencial): breves considerações. Revista LTr, São Paulo, v. 73, n.1, p. 28, jan. 2009. 
BOUCINHAS FILHO, Jorge Cavalcanti; ALVARENGA, Rubia Zanotelli de. O dano existencial e o direito do trabalho. Revista Síntese Trabalhista e Previdenciária, Ano XXIV, n. 284, fev. 2013.

BRASIL. Decreto-lei 5.452, de 1 de maio de 1943. Aprova a Consolidação das leis do trabalho. Disponível em: <http://www.planalto.gov.br/ccivil_03/decreto-lei/Del5452.htm>. Acesso em: 15 ago. 2015.

BRASIL. Lei 605, de 5 de janeiro de 1949. Repouso semanal remunerado e o pagamento de salário nos dias feriados civis e religiosos. Disponível em:< http://www.planalto.gov.br/ccivil_03/leis/L0605.htm>. Acesso em: 15 ago. 2015.

BRASIL. Constituição da República Federativa do Brasil de 1988. Disponível em:<http://www.planalto.gov.br/ccivil_03/constituicao/constituicao.htm>. Acesso em: 15 ago. 2015.

CASSAR, Vólia Bomfim. Princípios trabalhistas, novas profissões, globalização da economia e flexibilização das normas trabalhistas. Niterói, RJ: Impetus, 2010.

. Direito do trabalho. 5a ed. Niterói, RJ: Impetus, 2011.

FROTA, Hidemberg Alves da Frota. Noções fundamentais sobre o dano existencial. Revista Síntese Trabalhista e Previdenciária, Ano XXIV, n. 284, fev. 2013.

GRANDOV, Balldomero; BASCARY, Miguel Carrillo. Cicatrices. Dano estetico y derecho a la integridade física. Rosário: Editorial Faz, 2000.

NASCIMENTO, Sônia Mascaro. Dano existencial. Disponível em: $<$ http://www.soniamascaro.com.br/index.php/sonia-mascaro/artigos/257dano- existencial.html>. Acesso em: 14.08.2015.

RIO GRANDE DO SUL. Tribunal Regional do Trabalho $4^{\text {a }}$ região. 000153323.2012.5.04.0006 RO. DESEMBARGADOR ANDRÉ REVERBEL FERNANDES. Órgão 
Julgador: $\quad 4^{\mathrm{a}} \quad$ Turma. $\quad$ DEJT 21.07.2014. Disponível em:

$<$ http://www.trt4.jus.br/portal/portal/trt4/consultas/consulta_lista/ConsultaProcessualWindo $\mathrm{w}$ ? $\mathrm{svc}=$ consultaBean\&nroprocesso $=0001533$ -

23.2012.5.04.0006\&operation $=$ doProcesso\&action $=2 \&$ intervalo $=90>. \quad$ Acesso $\quad \mathrm{em}$ : 14.08 .2015

SOARES, Flaviana Rampazzo. Responsabilidade civil por dano existencial. Porto Alegre: Livraria do Advogado, 2009.

SOUTO MAIOR, Jorge Luiz. Do direito à desconexão do trabalho. Revista do Tribunal Regional do Trabalho da 15a Região, Campinas, n. 23, 2003. Disponível em: http://trt15.gov.br/escola_da_magistratura/Rev23Art17.pdf. Acesso em: 15.08.2010.

STJ. Superior Tribunal de Justiça. Súmula 227. Dj 08.10.1999.

Disponível

em: $<\mathrm{http}: / / \mathrm{www}$. stj.jus.br/SCON/sumulas/toc.jsp?tipo_visualizacao=RESUMO\&livre=\%40d ocn $\& \& b=S U M U \& p=$ false $\& \mathrm{t}=J U R I D I C O \& \mathrm{l}=10 \& \mathrm{i}=311>$. Acesso em: 15.08.2015.

TST. Tribunal Superior do Trabalho. RR - 1900-28.2010.5.03.0044; Relatora Ministra: Delaíde Miranda Arantes; Data de Julgamento: 14/11/2012; $7^{\mathrm{a}}$ Turma; Data de

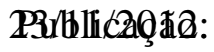
Disponível em: <file:///C:/Users/Angel/Downloads/32298_2012_1353661200000.pdf>. Acesso em: 14.08.2015.

STJ. Superior Tribunal de Justiça. Súmula 387. Dje 01.09.2009. Disponível em: $<$ http://www.stj.jus.br/SCON/sumulas/toc.jsp?tipo_visualizacao=RESUMO\&livre=\%40d $\mathrm{ocn} \& \& \mathrm{~b}=\mathrm{SUMU} \& \mathrm{p}=$ false $\& \mathrm{t}=\mathrm{JURIDICO} \& \mathrm{l}=10 \& \mathrm{i}=160>$. Acesso em: 14.08.2015. 